\title{
Removal of Sulfur Dioxide from Flue Gas Using the Sludge Sodium Humate
}

\author{
Yu Zhao and Guoxin Hu \\ School of Mechanical and Power Engineering, Shanghai Jiao Tong University, Shanghai 200240, China \\ Correspondence should be addressed to Guoxin Hu; huguoxin2011@163.com
}

Received 29 August 2013; Accepted 8 October 2013

Academic Editors: S. Fan and D. Musmarra

Copyright ( 2013 Y. Zhao and G. Hu. This is an open access article distributed under the Creative Commons Attribution License, which permits unrestricted use, distribution, and reproduction in any medium, provided the original work is properly cited.

\begin{abstract}
This study shows the ability of sodium humate from alkaline treatment sludge on removing sulfur dioxide $\left(\mathrm{SO}_{2}\right)$ in the simulated flue gas. Experiments were conducted to examine the effect of various operating parameters, like the inlet $\mathrm{SO}_{2}$ concentration or temperature or $\mathrm{O}_{2}$, on the $\mathrm{SO}_{2}$ absorption efficiency and desulfurization time in a lab-scale bubbling reactor. The sludge sodium humate in the supernatant after alkaline sludge treatment shows great performance in $\mathrm{SO}_{2}$ absorption, and such efficiency can be maintained above $98 \%$ with $100 \mathrm{~mL}$ of this absorption solution at $298 \mathrm{~K}$ (flue gas rate of $0.12 \mathrm{~m}^{3} / \mathrm{h}$ ). The highest $\mathrm{SO}_{2}$ absorption by $1.63 \mathrm{~g}$ SHA-Na is $0.946 \mathrm{mmol}$ in the process, which is translated to $0.037 \mathrm{~g} \mathrm{SO}_{2} \mathrm{~g}^{-1}$ SHA-Na. The experimental results indicate that the inlet $\mathrm{SO}_{2}$ concentration slightly influences the $\mathrm{SO}_{2}$ absorption efficiency and significantly influences the desulfurization time. The $\mathrm{pH}$ of the absorption solution should be above 3.5 in this process in order to make an effective desulfurization. The products of this process were characterized by Fourier transform infrared spectroscopy and X-ray diffraction. It can be seen that the desulfurization products mainly contain sludge humic acid sediment, which can be used as fertilizer components.
\end{abstract}

\section{Introduction}

Flue gas emissions, which mainly come from power plants by burning fossil fuels, have been causing serious air pollution for decades [1-3]. The reason for serious air pollution caused by flue gas emissions is that flue gas contains large amounts of sulfur dioxide $\left(\mathrm{SO}_{2}\right)$ and other pollutants [4]. Many researchers have been actively exploring technologies in effective flue gas desulfurization field [5-8]. Among these technologies, one of the most effective methods is the wet flue gas desulfurization which is mainly based on limestone [9]. However, it has many disadvantages, such as higher operating costs and greater water requirement and the potential to cause secondary pollution. Thus, cost-effective technologies in removing $\mathrm{SO}_{2}$ have become the focus of investigations.

Common commercial sodium humate, which is derived from peat, brown coal, and weathered coal, is a cheap absorbent. Green and Manahan started to use sodium humate to absorb $\mathrm{SO}_{2}$ from flue gas in the 1980s [10, 11]. Sun et al. were using humic acid as an additive to modify adsorbents for flue gas desulfurization [12]. Our team used sodium humate solution to remove $\mathrm{SO}_{2}$ and $\mathrm{NO}_{x}$ in flue gas $[13,14]$. Sludge sodium humate (SHA-Na) can be extracted from sludge through alkaline treatment method [15]. This paper proposed a new process for the removal of $\mathrm{SO}_{2}$ from flue gas by the absorption solution from sludge treatment and the production of fertilizer.

The new process shown in Figure 1 includes the following stages. (a) Excess sludge is disintegrated by sodium hydroxide in stirred reactor at $313 \mathrm{~K}$. (b) The disintegrated sludge is centrifuged and the supernatant is concentrated through membrane filter to spray into a desulfurization tower. (c) $\mathrm{SO}_{2}$ can be absorbed by SHA-Na in the desulfurization tower. The desulfurization liquid, which mainly contains sludge humic acid (SHA) and $\mathrm{H}_{2} \mathrm{SO}_{3}$, flows into the reactor. (d) In the reactor, $\mathrm{SO}_{3}{ }^{2-}$ is oxidized to $\mathrm{SO}_{4}{ }^{2-}$ through diffused aeration. (e) Afterward, the reaction liquid from the reactor flows into a sedimentation tank and stands for $12 \mathrm{~h}$. Due to the poor solubility of SHA, SHA may be separated as sediment from acidic solution. The separated SHA can be used as a kind of material for compound fertilizer after drying in spray dryer. From the above process, it is believed that the removal of $\mathrm{SO}_{2}$ by the supernatant from alkaline sludge treatment is a resourceful type of environmental protection technology for FGD. It 


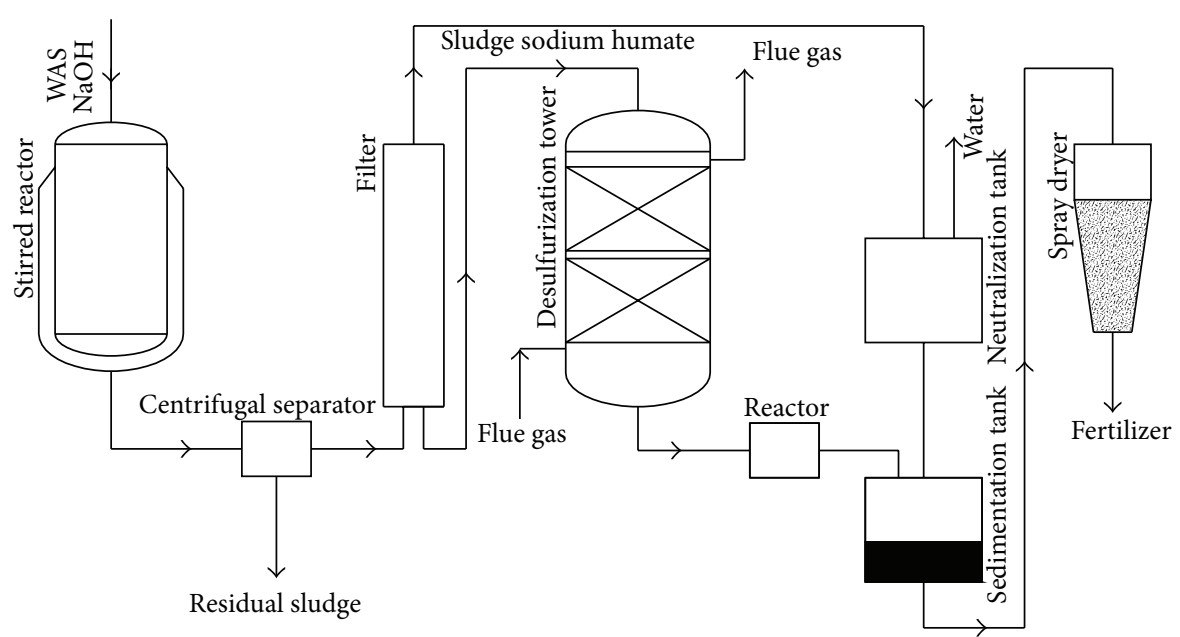

FIGURE 1: Simplified scheme of application of the SHA-Na for flue gas desulfurization.

carries the following advantages: (a) realizes sludge reduction and (b) utilizes the desulfurization product as a useful fertilizer. Therefore, it is hopeful to be applied in the future.

In this paper, we attempt to use a kind of absorption solution from alkaline treatment sludge to remove $\mathrm{SO}_{2}$ in flue gas. The effects of the inlet $\mathrm{SO}_{2}$ concentration, temperature, and presence or absence of $\mathrm{O}_{2}$, on the $\mathrm{SO}_{2}$ absorption efficiency, together with desulfurization time in a lab-scale bubbling reactor, are studied. Desulfurization products are characterized by Fourier transform infrared spectroscopy and $\mathrm{X}$-ray diffraction.

\section{Experimental Section}

2.1. Materials. Sludge samples were collected from the thickening tank of a wastewater treatment plant. The sludge samples carry water of approximately $98 \%$, a suspended solid (SS) content of $20.0 \mathrm{~g} / \mathrm{L}$, a volatile suspended solid (VSS) content of $16.0 \mathrm{~g} / \mathrm{L}$, and a soluble chemical oxygen demand (SCOD) of $270 \mathrm{mg} / \mathrm{L}$. Sodium hydroxide $(\mathrm{NaOH}, \mathrm{AR})$ was collected from chemical reagent. HA-Na was supplied with purity of $99 \%$. Sulfur dioxide gas with a purity of $99.95 \%$ was obtained from the market.

2.2. The Absorption Solution Extraction. A slightly modified method [16] was used to extract SHA-Na. The extraction of SHA-Na was conducted in $2.0 \mathrm{~L}$ batch mixed reactor that was placed in a water bath to maintain the temperature for this reaction at $313 \mathrm{~K}$ while the $\mathrm{NaOH}$ is at $0.2 \mathrm{~mol} / \mathrm{L}$. Following alkaline sludge treatment, the samples were centrifuged at $5000 \mathrm{r} / \mathrm{m}$ for $10 \mathrm{~min}$. After alkaline sludge treatment and centrifugal separation, the sample was filtered through a membrane with a mesh size of $0.45 \mu \mathrm{m}$.

2.3. Desulfurization Test. A schematic diagram of the experimental setup used in this study is shown in our previous paper [17]. The $\mathrm{SO}_{2}$ gas supplied from cylinder was diluted with $\mathrm{O}_{2}$ and $\mathrm{N}_{2}$ in the gas-mixing chamber. Then, this gaseous mixture flew through the bubbling reactor at ambient pressure. Rota meters and valves were used to monitor the gas flow. The concentrations of the simulated flue gas components $\left(\mathrm{SO}_{2}\right.$ and $\left.\mathrm{O}_{2}\right)$ were controlled by adjusting their flow rate and were monitored by a flue gas analyzer. In the progress of this experiment, the total rate of the gas stream was controlled at $0.12 \mathrm{~m}^{3} / \mathrm{h}$ during the experiment.

2.4. Characterization Methods. In the experiment, the inlet and outlet concentrations of $\mathrm{SO}_{2}$ were measured by a flue gas analyzer. The $\mathrm{pH}$ value measuring was conducted with a $\mathrm{pH}$ meter using a combination $\mathrm{pH}$ electrode $\mathrm{PHB}-5$. Before each $\mathrm{pH}$ value was read, the $\mathrm{pH}$ buffer solution was used to check the measurements of the electrode. Water content, SS, and volatile dissolved solids (VDS) were measured according to the standard methods [18]. SHA-Na was measured according to the spectrophotometer method recommended by Ye [19]. The protein content was measured using the Coomassie brilliant blue method [20]. FTIR spectra were recorded in the $4000-500 \mathrm{~cm}^{-1}$ range using an EQUINOX 55 FTIR spectrometer, continuously purged with dry air. Spectra were obtained from pressed $\mathrm{KBr}$ pellets. Pellets $(1 \mathrm{~cm}$ diameter) were prepared by mixing 1 or $2 \mathrm{mg}$ samples with $200 \mathrm{mg} \mathrm{KBr}$. Desulfurization products were characterized by XRD with a D/max-2200/PC type-ray diffraction instrument to study the composition of them. The heavy metals in products were analyzed by inductively coupled plasma atomic emission spectrometry.

\section{Results and Discussion}

3.1. Characteristics of the Supernatant after Alkaline Treatment Sludge. The sludge samples were centrifuged after alkaline treatment, and the supernatant was analyzed. Characteristics of the supernatant after alkaline treatment are shown in Table 1. The supernatant has a high $\mathrm{pH}$ value which is similar to the common commercial sodium humate. The VDS indicated that there was a high content of organic substances including sodium humate, protein, polysaccharides, nucleic acid, and lipids [21]. It can be seen that sodium humate and 
TABLE 1: Characteristics of the supernatant after alkaline treatment.

\begin{tabular}{lcccc}
\hline Parameters & Value & Organic substances & Value & \\
\hline $\mathrm{pH}$ & 10.8 & Sodium humate & $1.63 \mathrm{~g} / \mathrm{L}$ & $24.1 \%$ \\
$\mathrm{SS}$ & $0.07 \mathrm{~g} / \mathrm{L}$ & Protein & $2.0 \mathrm{~g} / \mathrm{L}$ & $29.6 \%$ \\
$\mathrm{VDS}$ & $6.756 \mathrm{~g} / \mathrm{L}$ & Othersa & $3.126 \mathrm{~g} / \mathrm{L}$ & $46.3 \%$ \\
\hline
\end{tabular}

protein were the primary constituents in this supernatant. Sodium humate accounted for approximately $25 \%$ of all of the dissolved organic matter by weight. After alkaline sludge treatment, the humic acid concentration in the supernatant was $1.63 \mathrm{~g} / \mathrm{L}$. However, the concentration of sodium humate in the absorption solution should be $10 \sim 40 \mathrm{~g} / \mathrm{L}$ in order to get a better absorption solution of $\mathrm{SO}_{2}$ in our previous papers. Therefore, when the supernatant was concentrated 10 times by ultrafiltration, the content of sodium humate in the retentate reached the required concentration in the process.

3.2. Absorption Process of $\mathrm{SO}_{2}$ in the Absorption Solution. The change of the $\mathrm{SO}_{2}$ concentration in outlet flue gas with time is shown in Figure 2. It can be observed that the $\mathrm{SO}_{2}$ absorption curve in absorption solution is divided into three sections: a descending section, a nearly horizontal section, and an ascending section. Also, the $\mathrm{pH}$ of the absorption solution in this process was clearly illustrated in Figure 2. The change of $\mathrm{pH}$ in the absorption solution is related to the $\mathrm{SO}_{2}$ concentration in outlet flue gas. In the descending section of $\mathrm{SO}_{2}$ absorption curve, the $\mathrm{pH}$ value of the absorption solution drops rapidly from 10.8 to 7.4, because of the faster consumption of $\mathrm{OH}^{-}$in the absorption solution. The $\mathrm{pH}$ value of the absorption solution decreases slowly from 7.4 to 3.4 in the nearly horizontal section of $\mathrm{SO}_{2}$ absorption curve, as the SHA-Na in the absorption solution is a sort of $\mathrm{pH}$ buffer solution [22], this behavior was interpreted as a buffer action of $-\mathrm{COOH}$ [23], which may lower the rate of $\mathrm{pH}$ value decrease. In the ascending section of $\mathrm{SO}_{2}$ absorption curve the $\mathrm{pH}$ value of SHA-Na maintains a constant number. It can be explained as follows: the absorption solution loses the desulfurization capability as the SHA-Na in the absorption solution has converted to SHA sediment. From the above analyses, it can be seen that when the $\mathrm{pH}$ value of the absorption solution drops to 3.4, the absorption solution will loose the desulfurization capability. Hence, the $\mathrm{pH}$ value of the absorption solution should be above 3.4 in this process in order to make it an effective desulfurization.

3.3. Analysis of the Desulfurization Mechanism. In removing $\mathrm{SO}_{2}$ process with this absorption solution, the main reactions are that $\mathrm{SO}_{2}$ from simulated flue gas react with SHA-Na, which is an acid-base reaction, and the acid-base theory predicts that SHA-Na should react with $\mathrm{SO}_{2}$ by following neutralization reaction $[10,11]$ :

$$
\begin{aligned}
& \text { SHA-Na (aq) }+\mathrm{SO}_{2}(\mathrm{~g})+\mathrm{H}_{2} \mathrm{O} \\
& \longleftrightarrow \mathrm{SHA}(\mathrm{s})+\mathrm{HSO}_{3}{ }^{-}(\mathrm{aq})+\mathrm{Na}^{+}(\mathrm{aq})
\end{aligned}
$$

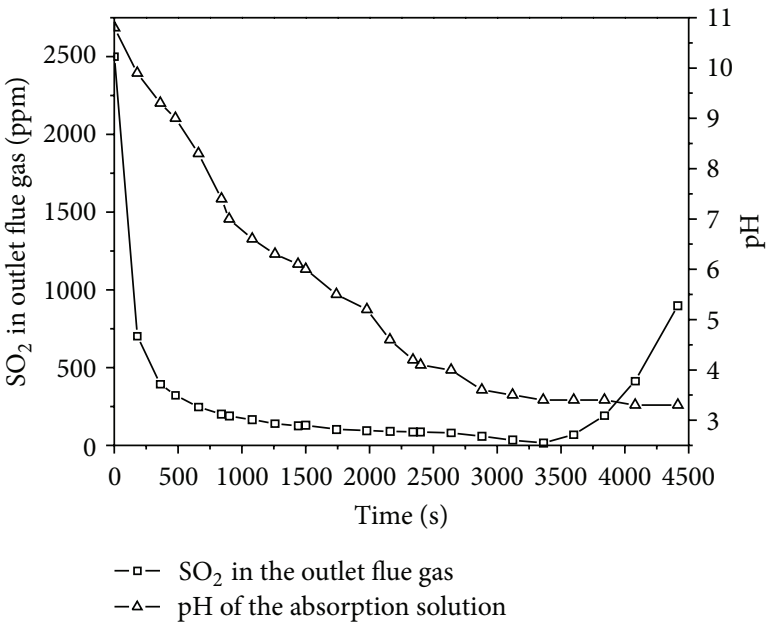

Figure 2: The profile absorption process of $\mathrm{SO}_{2}$ in absorption solution. $\left(\mathrm{SO}_{2}, 2500 \mathrm{ppm}\right.$; gas flow, $0.12 \mathrm{~m}^{3} / \mathrm{h}$; absorption solution $100 \mathrm{~mL} ; \mathrm{O}_{2}, 5 \mathrm{vol} \% ; 298 \mathrm{~K}$ ).

Simultaneously, when $\mathrm{SO}_{2}$ is dissolved in the absorption solution, based on its alkalinity, the following reactions occur $[24,25]$ :

$$
\begin{gathered}
\mathrm{SO}_{2}(\mathrm{~g}) \longleftrightarrow \mathrm{SO}_{2}(\mathrm{aq}) \\
\mathrm{SO}_{2}(\mathrm{aq})+\mathrm{H}_{2} \mathrm{O} \longleftrightarrow \mathrm{H}_{2} \mathrm{SO}_{3}(\mathrm{aq}) \\
\mathrm{H}_{2} \mathrm{SO}_{3}(\mathrm{aq}) \longleftrightarrow \mathrm{H}^{+}(\mathrm{aq})+\mathrm{HSO}_{3}{ }^{-}(\mathrm{aq}) \\
\mathrm{HSO}_{3}{ }^{-}(\mathrm{aq}) \longleftrightarrow \mathrm{H}^{+}(\mathrm{aq})+\mathrm{SO}_{3}{ }^{2-}(\mathrm{aq})
\end{gathered}
$$

Generally, the above reactions can be described by the following equilibrium equations (6) and (7):

$$
\begin{gathered}
\mathrm{SO}_{2}(\mathrm{aq})+\mathrm{OH}^{-} \longleftrightarrow \mathrm{HSO}_{3}{ }^{-}(\mathrm{aq}) \\
\mathrm{HSO}_{3}{ }^{-}(\mathrm{aq})+\mathrm{OH}^{-} \longleftrightarrow \mathrm{SO}_{3}{ }^{2-}(\mathrm{aq})+\mathrm{H}_{2} \mathrm{O}
\end{gathered}
$$

Then, $\mathrm{SO}_{3}{ }^{2-}$ is oxidized to $\mathrm{SO}_{4}{ }^{2-}$ by catalysis with transition metal ions, which is the step for (6) and (7) to move to the right. The dissolved $\mathrm{SO}_{2}$ also produced $\mathrm{H}^{+}$by ionization in this process. The acidic groups of SHA-Na, such as carboxyl $\left(\mathrm{COO}^{-}\right)$and hydroxyl $\left(\mathrm{OH}^{-}\right)$, can react rapidly with $\mathrm{H}^{+}$, and SHA-Na is transferred to sludge humic acid. According to (1) and (5), this reaction also moves the reaction equilibrium to the right, which results in the fact that more $\mathrm{SO}_{2}$ is dissolved into the absorption solution. When entire SHA-Na is consumed, the desulfurization reaction is terminated in the process. 
TABLE 2: The $\mathrm{SO}_{2}$ absorption using different absorption solution ${ }^{\mathrm{a}}$.

\begin{tabular}{lccc}
\hline Sample & Maximum absorption efficiency of $\mathrm{SO}_{2}(\%)$ & DTHE $(\mathrm{s})$ & \\
\hline $\mathrm{SHA}-\mathrm{Na}$ & 98.32 & 4357 & 0.946 \\
$\mathrm{NaOH}$ & 81.04 & 478 & 0.080 \\
$\mathrm{H}_{2} \mathrm{O}$ & 78.52 & 240 & 0.038 \\
Activated sludge & 90.32 & 408 & 0.075 \\
Excess sludge & 92.40 & 840 & 0.166 \\
\hline
\end{tabular}

${ }^{\mathrm{a}} C_{0}: 2500 \mathrm{ppm} ; q$ : $0.12 \mathrm{~m}^{3} / \mathrm{h}$; absorption solution: $100 \mathrm{~mL} ; \mathrm{O}_{2}: 5$ vol\%; $298 \mathrm{~K}$; ambient pressure.

3.4. Desulfurization Performance of SHA-Na. Several additional experiments were done to gain a further understanding of desulfurization performance of SHA-Na. The contrast experiments of removing $\mathrm{SO}_{2}$, one used water at the same volume and another used $\mathrm{NaOH}$ solution at the same $\mathrm{pH}$ (10.8), were conducted, respectively. Total $\mathrm{SO}_{2}$ absorption can be calculated by (8)

$$
\begin{gathered}
Q=\int_{0}^{T} \frac{\left(\eta \times q \times C_{0} \times M\right)}{22.4 \times 3600 \times 10^{3}} d t, \\
Q=\frac{q \times C_{0} \times M}{8.064 \times 10^{7}} \int_{0}^{T} \eta d t,
\end{gathered}
$$

where $Q$ stands for the amount of $\mathrm{SO}_{2}$ absorption, mmol and $\eta$ stands for the removal efficiency of $\mathrm{SO}_{2}, \%$. The formula of the $\mathrm{SO}_{2}$ absorption efficiency can be obtained from the literature [17]. $q$ stands for the gas flow, $\mathrm{m}^{3} / \mathrm{h} ; C_{0}$ stands for the inlet concentration of $\mathrm{SO}_{2}$, ppm; $M$ stands for the molar mass $\mathrm{SO}_{2}, \mathrm{~g} / \mathrm{mol} ; \mathrm{T}$ stands for the reaction time, $\mathrm{s}$.

It is clear as shown in Table 2 that experimental results illustrate that SHA-Na performance much better than that of water and $\mathrm{NaOH}$ in both the $\mathrm{SO}_{2}$ absorption efficiency and the duration time of high efficiency ((DTHE), the time of the $\mathrm{SO}_{2}$ absorption efficiency is above $\left.70 \%\right)$. Water absorbs the $\mathrm{SO}_{2}$ more slowly because it is only a physical absorption process controlled by molecular diffusion [26]. However, when we use SHA-Na in this absorption solution to remove $\mathrm{SO}_{2}$, the hydroxyl radicals in SHA-Na can react rapidly with the $\mathrm{SO}_{2}$. Thus, it leads to the decrease of the $\mathrm{SO}_{2}$ concentration in the gas-liquid interface. The $\mathrm{SO}_{2}$ diffusion can be promoted due to this decrease of the $\mathrm{SO}_{2}$ concentration in the gasliquid interface. Furthermore, SHA-Na can react with $\mathrm{H}^{+}$ as what common commercial sodium humate does, and it is transformed into humic acid sediment. Therefore, it can be concluded that the desulfurization capability of SHA$\mathrm{Na}$ mainly depends upon the consumption of the hydroxyl radicals as well as common commercial sodium humate. Compared with $\mathrm{NaOH}$ solution, it is also shown in Table 2 that the desulfurization capability of SHA-Na is stronger than $\mathrm{NaOH}$ solution at the same volume and $\mathrm{pH}$ value in Table 2. It can be explained that the hydroxyl radicals of $\mathrm{NaOH}$ solution are less than those of SHA-Na at the same volume and $\mathrm{pH}$ value. The contrast experiments of removing $\mathrm{SO}_{2}$ with different sludge as the absorption solution at the same volume are also conducted, respectively. The experimental results illustrate that SHA-Na performance is also much better than that of activated sludge and excess sludge in both the $\mathrm{SO}_{2}$

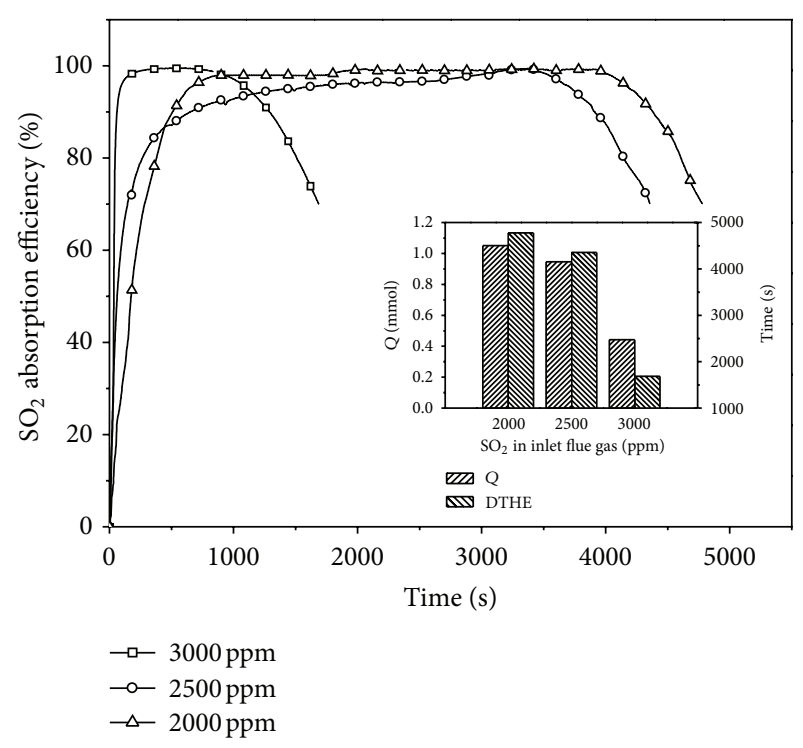

Figure 3: The effect of the inlet $\mathrm{SO}_{2}$ concentration (gas flow, $0.12 \mathrm{~m}^{3} / \mathrm{h}$; absorption solution, $100 \mathrm{~mL} ; \mathrm{O}_{2}, 5 \mathrm{vol} \% ; 298 \mathrm{~K}$ ). The inset shows the absorption amount of $\mathrm{SO}_{2}$ and DTHE.

absorption efficiency and DTHE. It can be explained that the $\mathrm{SO}_{2}$ absorption efficiency and desulfurization time depend on the content of fulvic acid that can excellently absorb $\mathrm{SO}_{2}$ in the activated sludge or excess sludge [25]. The content of fulvic acid in the activated sludge is lower than the content of fuluic acid in the excess sludge, so the $\mathrm{SO}_{2}$ absorption efficiency of the activated sludge is lower than that of the excess sludge and the desulfurization time of the activated sludge is shorter than that of the excess sludge. Therefore, SHA-Na can be practically used as a kind of absorbent for the removal of $\mathrm{SO}_{2}$.

3.5. Effect of the Inlet $\mathrm{SO}_{2}$ Concentration. The effect of the inlet $\mathrm{SO}_{2}$ concentration on absorption efficiency is displayed in Figure 3. The inlet $\mathrm{SO}_{2}$ concentration does not have significant effect on the $\mathrm{SO}_{2}$ absorption efficiency under this condition, and the $\mathrm{SO}_{2}$ absorption efficiency showed a constant value of about $98 \%$ in nearly horizontal section. However, the desulfurization time in this section decreases greatly with the increase of the inlet $\mathrm{SO}_{2}$ concentration. This can be explained as follows: according to the model [27], the absorption of $\mathrm{SO}_{2}$ requires the removal of aqueous $\mathrm{SO}_{2}$ from the gas-liquid interface. The reaction with SHA-Na produced 


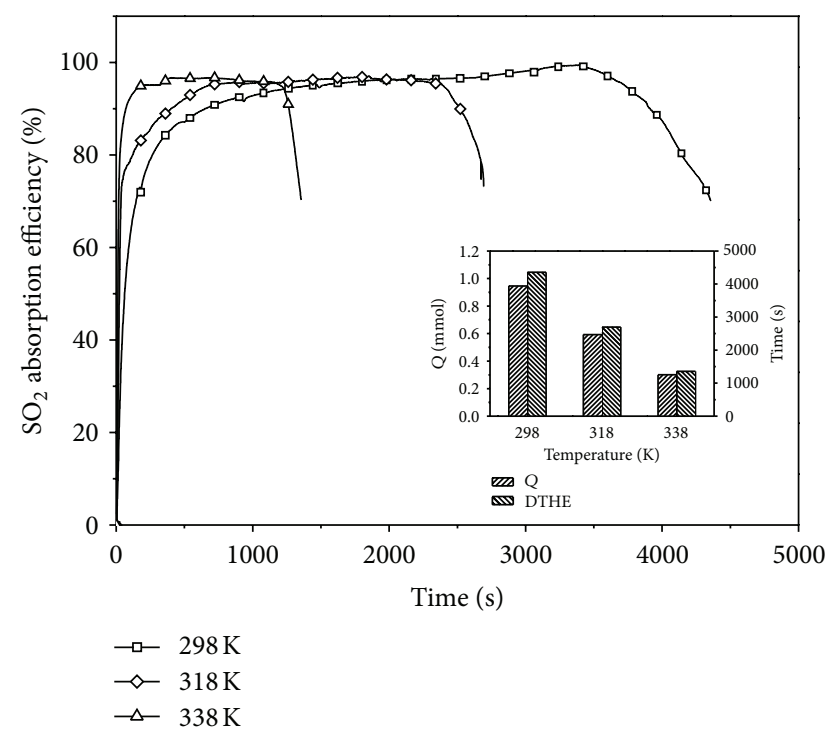

FIGURE 4: The effect of the temperature $\left(\mathrm{SO}_{2}, 2500 \mathrm{ppm}\right.$; gas flow, $0.12 \mathrm{~m}^{3} / \mathrm{h}$; absorption solution, $100 \mathrm{~mL} ; \mathrm{O}_{2}, 5 \mathrm{vol} \%$ ). The inset shows the absorption amount of $\mathrm{SO}_{2}$ and DTHE.

by sludge allows the concentration of $\mathrm{SO}_{2}$ in the absorption solution to decrease. However, the absorption effect of $\mathrm{SO}_{2}$ becomes worse because of higher concentration of $\mathrm{SO}_{2}$ at the gas-liquid interface when the inlet $\mathrm{SO}_{2}$ concentration increases. Hence the desulfurization time in the nearly horizontal section decreased. And the absorption amount of $\mathrm{SO}_{2}$ at the inset in Figure 3, which decreases with the increase of the inlet $\mathrm{SO}_{2}$ concentration, shows a reasonable agreement with it.

3.6. Effect of the Temperature. The effect of the temperature on the $\mathrm{SO}_{2}$ absorption efficiency was also conducted. The experimental results are shown in Figure 4. It indicates that the absorption temperature has slight effect on the $\mathrm{SO}_{2}$ absorption efficiency and the desulfurization time in the nearly horizontal section becomes shorter with the rise of the temperature. The $\mathrm{SO}_{2}$ absorption efficiency increases slightly as the absorption temperature ascends from $298 \mathrm{~K}$ to $338 \mathrm{~K}$. However, the desulfurization time in the nearly horizontal section decreases from $3500 \mathrm{~s}$ to $1300 \mathrm{~s}$ as the absorption temperature ascends from $298 \mathrm{~K}$ to $338 \mathrm{~K}$. It can be explained as follows. On one hand, according to the dissolution equilibrium of $\mathrm{SO}_{2}$, the equilibrium partial pressure of $\mathrm{SO}_{2}$ is increasing with the rise of the temperature, which results in the escape of some dissolved $\mathrm{SO}_{2}$ from solution. In addition, the limit of "diffusional regime" is probably reached and this limit depends on temperature proposed by Lancia and Musmarra [28]. The solubility of $\mathrm{SO}_{2}$ decreases with the rise of the absorption temperature in water. On the other hand, the contact time of flue gas and liquid is reduced because the relative velocity of gas molecules speeds up at high temperature. Hence, the absorption amount of $\mathrm{SO}_{2}$ decreases with the increase of the temperature at the inset in Figure 4. Although the removal of $\mathrm{SO}_{2}$ is promoted at low temperature, removing $\mathrm{SO}_{2}$ with SHA-Na solution in the

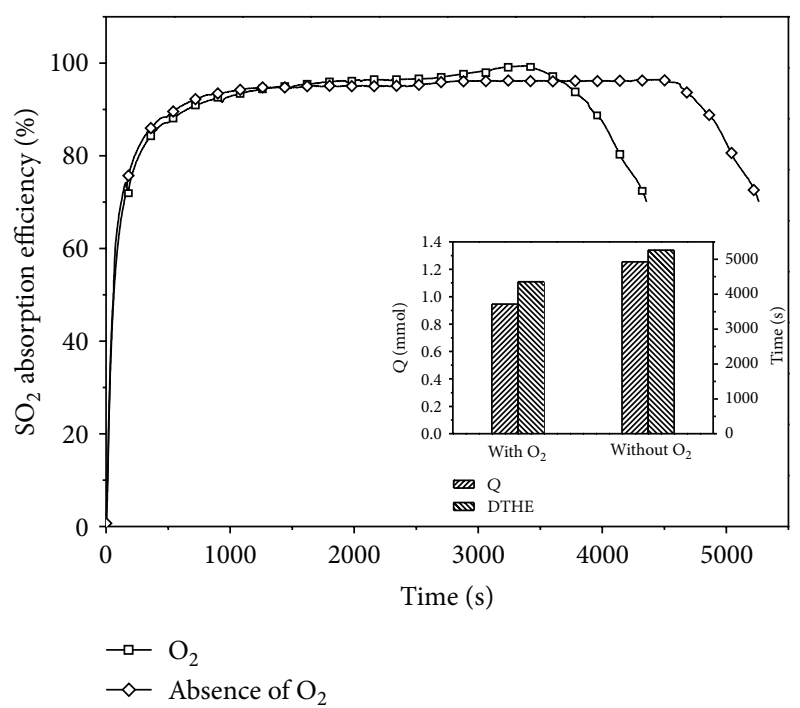

FIgure 5: The effects of $\mathrm{O}_{2}\left(\mathrm{SO}_{2}, 2500 \mathrm{ppm}\right.$; gas flow, $0.12 \mathrm{~m}^{3} / \mathrm{h}$; absorption solution, $100 \mathrm{~mL} ; 298 \mathrm{~K}$ ). The inset shows the absorption amount of $\mathrm{SO}_{2}$ and DTHE.

ambient condition at room temperature should be suitable for this process to reduce the desulfurization cost.

3.7. Effect of Oxygen. Flue gas from power plant usually consists of about $5 \mathrm{vol} \% \mathrm{O}_{2}$, trace gases, 15 to $20 \mathrm{vol} \% \mathrm{CO}_{2}$, and balance $\mathrm{N}_{2}$ [29]. Hence, oxygen (a concentration of $5 \mathrm{vol} \%)$ was introduced into a simple simulated flue gas $\left(\mathrm{N}_{2}+\right.$ $\mathrm{SO}_{2}$ ), that is, the simulated flue gas for this study, to understand the potential influence of the presence of $\mathrm{O}_{2}$ on the SHA-Na performances and interaction of $\mathrm{SO}_{2}$ and SHA-Na in the absorption solution. Test was conducted without the presence of $\mathrm{O}_{2}$, where relative to the presence of $\mathrm{O}_{2}$, which is shown in Figure 5. The $\mathrm{SO}_{2}$ absorption efficiency has a slight decrease under an aerobic condition, while the absorption amount of $\mathrm{SO}_{2}$ and DTHE has little increase. It is known that the dissolved $\mathrm{O}_{2}$ in the absorption solution may accelerate the oxidation of sulfite into sulfate. Sulphite oxidation rate can be greatly improved by very low metal concentration $[30,31]$. The mass-transfer resistance of the liquid phase in absorption solution is lessened, which results in the promotion of the $\mathrm{SO}_{2}$ mass transfer. Thus, the $\mathrm{SO}_{2}$ absorption efficiency with the presence of oxygen is higher than that with the absence of $\mathrm{O}_{2}$. However, it maybe that the consumption of $\mathrm{O}_{2}$ makes a corresponding growth of the inlet $\mathrm{SO}_{2}$ concentration, which results in the lower absorption amount of $\mathrm{SO}_{2}$ and DTHE. Based on the flue gas, the oxygen concentration was maintained at $5 \%$ in the simulated flue gas of $\mathrm{N}_{2}, \mathrm{O}_{2}$ and for subsequent experiments.

3.8. Analysis of Desulfurization Product. After the desulfurization process, the absorption liquid shown in Figure 6 was separated into liquid and solid by filtration. The crystals were gained by drying the supernatant layer from the absorption liquid. 
TABLE 3: The contents of humic acid and heavy metals in the product and the comparison with the standard.

\begin{tabular}{lcc}
\hline Indexes & In the standard & In the product \\
\hline Humic acid $(\mathrm{g} / \mathrm{L})$ & $\geq 30$ & 15.2 \\
$\mathrm{As}(\mathrm{mg} / \mathrm{L})$ & $\leq 10$ & 0.56 \\
$\mathrm{Cd}(\mathrm{mg} / \mathrm{L})$ & $\leq 10$ & 0.41 \\
$\mathrm{~Pb}(\mathrm{mg} / \mathrm{L})$ & $\leq 50$ & 5.31 \\
\hline
\end{tabular}

(SO $2: 2500$ ppm; gas flow: $0.12 \mathrm{~m}^{3} / \mathrm{h}$; absorption solution: $100 \mathrm{~mL} ; \mathrm{O}_{2}: 5$ vol\%; $25^{\circ} \mathrm{C}$.)

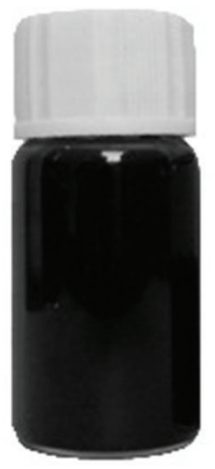

(A)

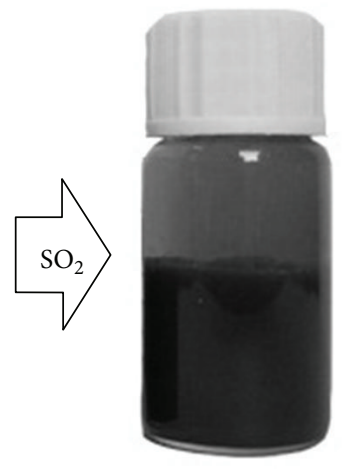

(B)
FIGURE 6: The photo of (A) SHA-Na solution; (B) desulfurization liquid after standing for 3 hours $\left(\mathrm{SO}_{2}, 2500 \mathrm{ppm}\right.$; gas flow, $0.12 \mathrm{~m}^{3} / \mathrm{h}$; absorption solution, $\left.100 \mathrm{~mL} ; \mathrm{O}_{2}, 5 \mathrm{vol} \% ; 25^{\circ} \mathrm{C}\right)$.

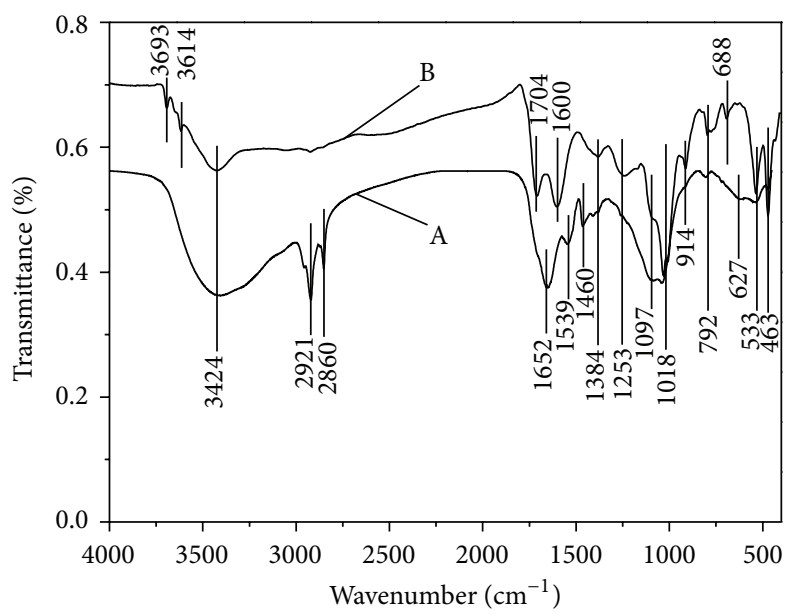

(A) The product of SHA-Na FGD

(B) The product of HA-Na FGD

FIGURE 7: FTIR spectra of desulfurization product $\left(\mathrm{SO}_{2}, 2500 \mathrm{ppm}\right.$; gas flow, $0.12 \mathrm{~m}^{3} / \mathrm{h}$; absorption solution, $100 \mathrm{~mL} ; \mathrm{O}_{2}, 5 \mathrm{vol} \% ; 25^{\circ} \mathrm{C}$ ).

FTIR spectroscopy is a powerful and nondestructive tool for the investigation of decomposition in the desulfurization product. Figure 7 shows the FTIR spectra comparison diagram of desulfurization products which are from SHA-Na desulfurization process and HA-Na desulfurization process, respectively. The main absorbance bands of them are in common a broad band at the wavenumbers of $3424 \mathrm{~cm}^{-1}$
( $\mathrm{H}$ bonds, $\mathrm{OH}$ groups), $1384 \mathrm{~cm}^{-1}\left(\mathrm{COO}^{-}, \mathrm{CH}_{3}\right)$, a small peak at $1253 \mathrm{~cm}^{-1}$ (aromatic C, C-O stretch), a slight shoulder around $1097 \mathrm{~cm}^{-1}$ (aliphatic $\mathrm{CH}_{2}, \mathrm{OH}$, or $\mathrm{C}-\mathrm{O}$ stretch of various groups), and a peak at $1050 \mathrm{~cm}^{-1}$ (C-O stretch of polysaccharide) $[32,33]$. Compared with spectra of humic acid, it is obvious that distinct differences in the spectra that resulted from the SHA-Na flue gas desulfurization process appear as peaks in the aliphatic region at 2921 and $2860 \mathrm{~cm}^{-1}$, [34] in which sludge humic acid contains a lot of fat material. Three new bands $\left(1652,1539\right.$, and $\left.1460 \mathrm{~cm}^{-1}\right)$ appear in the $1700-1450 \mathrm{~cm}^{-1}$ spectra of all the products of desulfurization. HAs are distinguished by the presence of a strong absorption band near $1650 \mathrm{~cm}^{-1}$, moderately strong absorption at $1540 \mathrm{~cm}^{-1}$, strong absorption near $1050 \mathrm{~cm}^{-1}$, and relatively pronounced absorption near $2900 \mathrm{~cm}^{-1}$ [35]. A unique feature of this spectrum also shows the presence of bands indicated proteins and carbohydrates. Due to its poor solubility, sludge humic acid may be separated as sediment from acidic aqueous solution and converted into humic acid compound fertilizer. The chief product of drying the supernatant layer was characterized by XRD. As shown in Figure 8, the diffraction peaks at the XRD patterns of the catalysts obviously belong to $\mathrm{Na}_{2} \mathrm{SO}_{4}[36,37]$.

Heavy metals are a limiting factor for sludge fertilizer. The heavy metal content of humic acids extracted from sludge depends on the dissolution rate of sludge heavy metals and the rejection rate of heavy metals by the membrane. During $\mathrm{NaOH}$ treatment, the dissolved heavy metals in sludge generally comprise less than $60 \%$ of the total heavy metals [38]. Under the strong alkaline conditions, only part of the amphoteric metal in proper forms can be dissolved. Therefore, the heavy metal content in the supernatant was low in Table 3. It can be seen that after the desulfurization process, the desulfurization product contains mainly sludge humic acid sediment, which may be used as fertilizer components.

\section{Conclusion}

In the present work, alkaline pretreatment of the activated sludge represented a suitable and effective method for the preparation of SHA-Na. The characteristics of $\mathrm{SO}_{2}$ absorption into the SHA-Na absorption solution have been investigated in a bubbling reactor. The experimental results show, that compared with water (with the same volume) and $\mathrm{NaOH}$ solution (with the same $\mathrm{pH}$ ), SHA-Na shows greater performance in $\mathrm{SO}_{2}$ absorption. The effects on the $\mathrm{SO}_{2}$ absorption efficiency and desulfurization time have been studied, while the inlet $\mathrm{SO}_{2}$ concentration and temperature were 


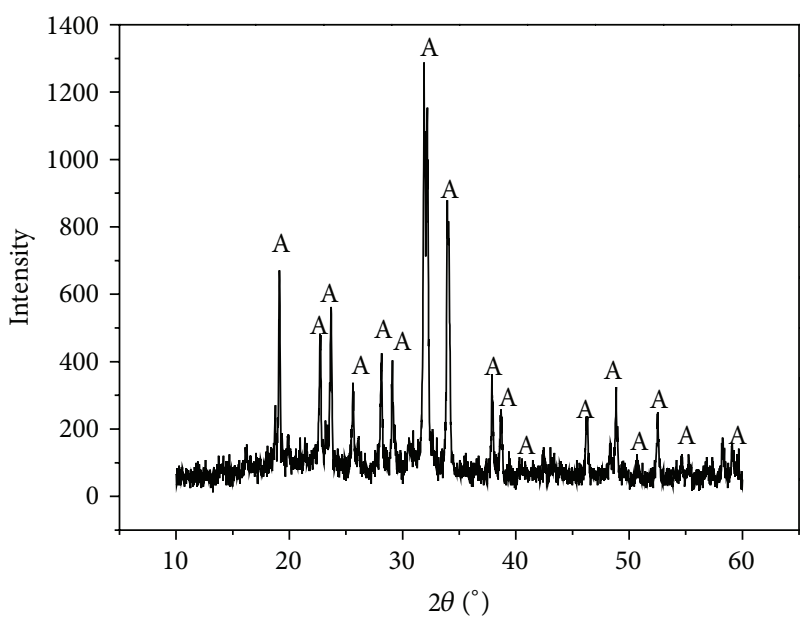

(A) $\mathrm{Na}_{2} \mathrm{SO}_{4}$

FIGURE 8: XRD pattern of the crystals from supernatant $\left(\mathrm{SO}_{2}\right.$, $2500 \mathrm{ppm}$; gas flow, $0.12 \mathrm{~m}^{3} / \mathrm{h}$; absorption solution, $100 \mathrm{~mL} ; \mathrm{O}_{2}$, 5 vol $\%$; $25^{\circ} \mathrm{C}$ ).

changed. Characterization of the desulfurization products was performed by FTIR and XRD analysis. It was found that the desulfurization products can be used as the compound fertilizer. The concept of combat environmental problems by methods such as removing a waste by using another waste source is of economic interest. Therefore, it is possible for the desulfurization process of SHA-Na to be used in future.

\section{Acknowledgments}

The authors gratefully acknowledge the financial support by the National Science Foundation of China (no. 51176113) and thank the Instrumental Analysis Center of SJTU for FTIR, XRD measurements.

\section{References}

[1] J. Fenger, "Air pollution in the last 50 years-from local to global," Atmospheric Environment, vol. 43, no. 1, pp. 13-22, 2009.

[2] D. G. Streets and S. T. Waldhoff, "Present and future emissions of air pollutants in China: $\mathrm{SO}_{2}, \mathrm{NO}_{x}$, and CO," Atmospheric Environment, vol. 34, no. 3, pp. 363-374, 2000.

[3] A. M. Omer, "Energy, environment and sustainable development," Renewable and Sustainable Energy Reviews, vol. 12, no. 9, pp. 2265-2300, 2008.

[4] E. S. Rubin, “Toxic releases from power plants," Environmental Science and Technology, vol. 33, no. 18, pp. 3062-3067, 1999.

[5] R. K. Srivastava and W. Jozewicz, "Flue gas desulfurization: the state of the art," Journal of the Air and Waste Management Association, vol. 51, no. 12, pp. 1676-1688, 2001.

[6] A. Demirbaş and M. Balat, "Coal desulfurization via different methods," Energy Sources, vol. 26, no. 6, pp. 541-550, 2004.

[7] J. Zhang, C. You, and C. Chen, "Effect of internal structure on flue gas desulfurization with rapidly hydrated sorbent in a circulating fluidized bed at moderate temperatures," Industrial and Engineering Chemistry Research, vol. 49, no. 22, pp. 1146411470, 2010.
[8] Y. Zhou, M. Zhang, D. Wang, and L. Wang, "Study on a novel semidry flue gas desulfurization with multifluid alkaline spray generator," Industrial and Engineering Chemistry Research, vol. 44, no. 23, pp. 8830-8836, 2005.

[9] A. Lancia, D. Musmarra, F. Pepe, and G. Volpicelli, " $\mathrm{SO}_{2}$ absorption in a bubbling reactor using limestone suspensions," Chemical Engineering Science, vol. 49, no. 24, pp. 4523-4532, 1994.

[10] J. B. Green and S. E. Manahan, "Absorption of sulphur dioxide by sodium humates," Fuel, vol. 60, no. 6, pp. 488-494, 1981.

[11] J. B. Green and S. E. Manahan, "Sulfur dioxide sorption by humic acid-fly ash mixtures," Fuel, vol. 60, no. 4, pp. 330-334, 1981.

[12] Z. Sun, H. Gao, G. Hu, and Y. Li, "Preparation of sodium humate $/ \alpha$-aluminum oxide adsorbents for flue gas desulfurization," Environmental Engineering Science, vol. 26, no. 7, pp. 1249 1255, 2009.

[13] Y. Zhao, G. Hu, Z. Sun, and J. Yang, "Simultaneous removal of $\mathrm{SO}_{2}$ and $\mathrm{NO}_{2}$ on $\alpha-\mathrm{Al}_{2} \mathrm{O}_{3}$ absorbents loaded with sodium humate and ammonia water," Energy and Fuels, vol. 25, no. 7, pp. 2927-2931, 2011.

[14] G. Hu, Z. Sun, and H. Gao, "Novel process of simultaneous removal of $\mathrm{SO}_{2}$ and $\mathrm{NO}_{2}$ by sodium humate solution," Environmental Science and Technology, vol. 44, no. 17, pp. 6712-6717, 2010.

[15] A. Posner, "The humic acids extracted by various reagents from a soil," European Journal of Soil Science, vol. 17, no. 1, pp. 65-78, 2006.

[16] H. Li, Y. Jin, and Y. Nie, "Application of alkaline treatment for sludge decrement and humic acid recovery," Bioresource Technology, vol. 100, no. 24, pp. 6278-6283, 2009.

[17] Z. Sun, Y. Zhao, H. Gao, and G. Hu, "Removal of $\mathrm{SO}_{2}$ from flue gas by sodium humate solution," Energy and Fuels, vol. 24, no. 2, pp. 1013-1019, 2010.

[18] APHA, Standard Methods for the Examination of Water and Wastewater, American Public Health Association, Washington, DC, USA, 19th edition, 1995.

[19] Z. Ye, "Spectrophotometric method used for determination of the content of humic acid in sewage sludge," Environmental Science and Technology, vol. 44, no. 1, pp. 34-36, 1989.

[20] X. Wang and S. Qin, The Basis of Biochemical Experiments, Higher Education Press, Beijing, China, 2003.

[21] L. Wei, K. Wang, Q. Zhao, J. Jiang, C. Xie, and W. Qiu, "Organic matter extracted from activated sludge with ammonium hydroxide and its characterization," Journal of Environmental Sciences, vol. 22, no. 5, pp. 641-647, 2010.

[22] G. P. Curtis and M. Reinhard, "Reductive dehalogenation of hexachloroethane, carbon tetrachloride, and bromoform by anthrahydroquinone disulfonate and humic acid," Environmental Science Technology, vol. 28, no. 13, pp. 2393-2401, 1994.

[23] J. P. Zhang, A. Li, and A. Q. Wang, "Study on superabsorbent composite. V. Synthesis, swelling behaviors and application of poly(acrylic acid-co-acrylamide)/sodium humate/attapulgite superabsorbent composite," Polymers for Advanced Technologies, vol. 16, no. 11-12, pp. 813-820, 2005.

[24] U. Ipek, "Sulfur dioxide removal by using leather factory wastewater," Clean, vol. 38, no. 1, pp. 17-22, 2010.

[25] J. Yang and $\mathrm{G}$. $\mathrm{Hu}$, "Absorption of $\mathrm{SO}_{2}$ from flue gas by aqueous fulvic acid solution," RSC Advances, vol. 2, pp. 11410-11418, 2012.

[26] F. P. Terraglio and R. M. Manganelli, "The absorption of atmospheric sulfur dioxide by water solutions," Journal of the Air Pollution Control Association, vol. 17, no. 6, pp. 403-406, 1967. 
[27] A. Lancia, D. Musmarra, and F. Pepe, "Modeling of $\mathrm{SO}_{2}$ absorption into limestone suspensions," Industrial and Engineering Chemistry Research, vol. 36, no. 1, pp. 197-203, 1997.

[28] A. Lancia, D. Musmarra, F. Pepe, and M. Prisciandaro, "Model of oxygen absorption into calcium sulfite solutions," Chemical Engineering Journal, vol. 66, no. 2, pp. 123-129, 1997.

[29] S.-P. Kang and H. Lee, "Recovery of $\mathrm{CO}_{2}$ from flue gas using gas hydrate: thermodynamic verification through phase equilibrium measurements," Environmental Science and Technology, vol. 34 , no. 20 , pp. 4397-4400, 2000.

[30] D. Karatza, M. Prisciandaro, A. Lancia, and D. Musmarra, "Reaction rate of sulfite oxidation catalyzed by cuprous ions," Chemical Engineering Journal, vol. 145, no. 2, pp. 285-289, 2008.

[31] A. Lancia and D. Musmarra, "Calcium bisulfite oxidation rate in wet limestone-gypsum flue gas desulfurization process," Environmental Science and Technology, vol. 33, no. 11, pp. 19311935, 1999.

[32] S. F. Sim, L. Seng, N. Bt Majri, and H. Bt Mat, "A comparative evaluation on the oxidative approaches for extraction of humic acids from low rank coal of Mukah, Sarawak," Journal of the Brazilian Chemical Society, vol. 18, no. 1, pp. 34-40, 2007.

[33] F. J. Stevenson and K. M. Goh, "Infrared spectra of humic acids and related substances," Geochimica et Cosmochimica Acta, vol. 35, no. 5, pp. 471-483, 1971.

[34] S. Belfer, R. Fainchtain, Y. Purinson, and O. Kedem, "Surface characterization by FTIR-ATR spectroscopy of polyethersulfone membranes-unmodified, modified and protein fouled," Journal of Membrane Science, vol. 172, no. 1-2, pp. 113-124, 2000.

[35] J.-H. Hsu and S.-L. Lo, "Chemical and spectroscopic analysis of organic matter transformations during composting of pig manure," Environmental Pollution, vol. 104, no. 2, pp. 189-196, 1999.

[36] T. Tsuzuki and P. G. McCormick, "Synthesis of $\mathrm{Cr}_{2} \mathrm{O}_{3}$ nanoparticles by mechanochemical processing," Acta Materialia, vol. 48, no. 11, pp. 2795-2801, 2000.

[37] K. Linnow, A. Zeunert, and M. Steiger, "Investigation of sodium sulfate phase transitions in a porous material using humidity- and temperature-controlled x-ray diffraction," Analytical Chemistry, vol. 78, no. 13, pp. 4683-4689, 2006.

[38] C. Wang, X.-C. Li, H.-T. Ma, J. Qian, and J.-B. Zhai, “Distribution of extractable fractions of heavy metals in sludge during the wastewater treatment process," Journal of Hazardous Materials, vol. 137, no. 3, pp. 1277-1283, 2006. 

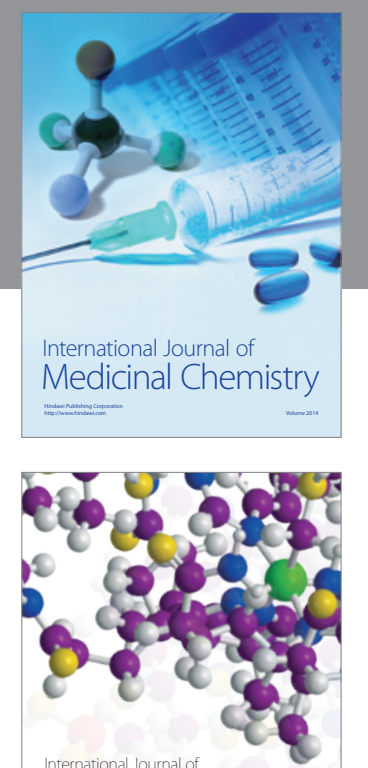

\section{Carbohydrate} Chemistry

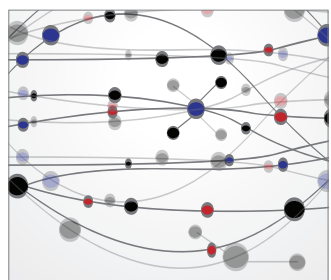

The Scientific World Journal
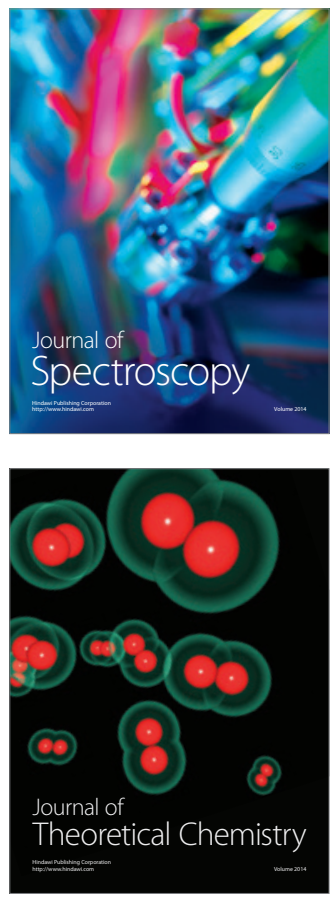
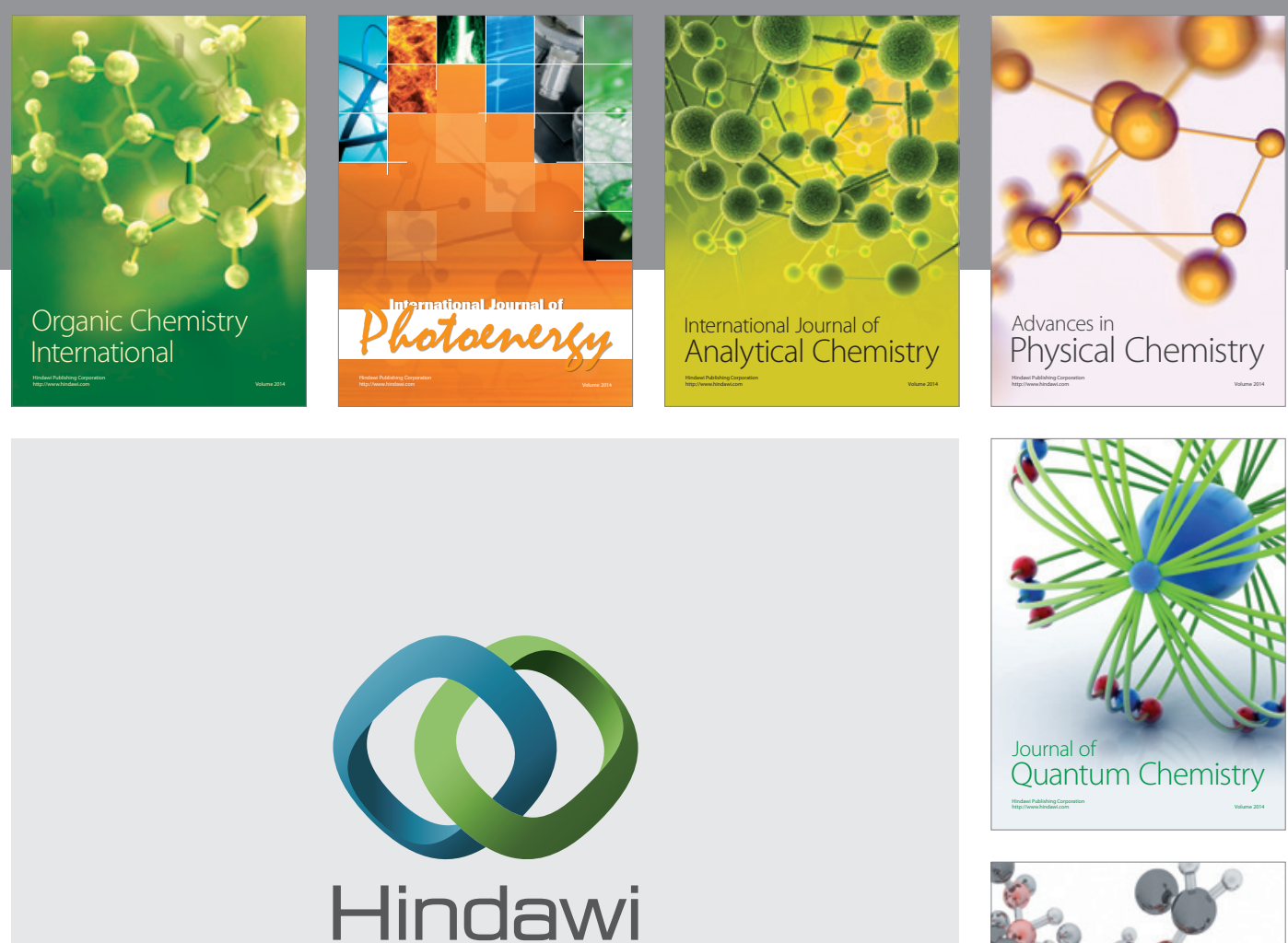

Submit your manuscripts at

http://www.hindawi.com

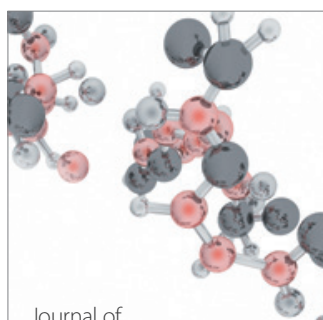

Analytical Methods

in Chemistry

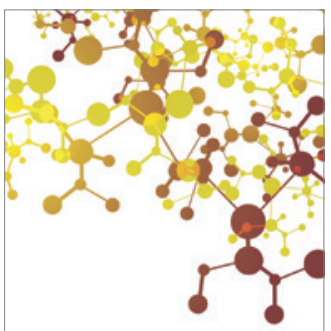

Journal of

Applied Chemistry

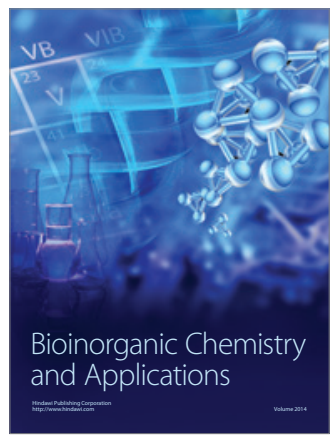

Inorganic Chemistry
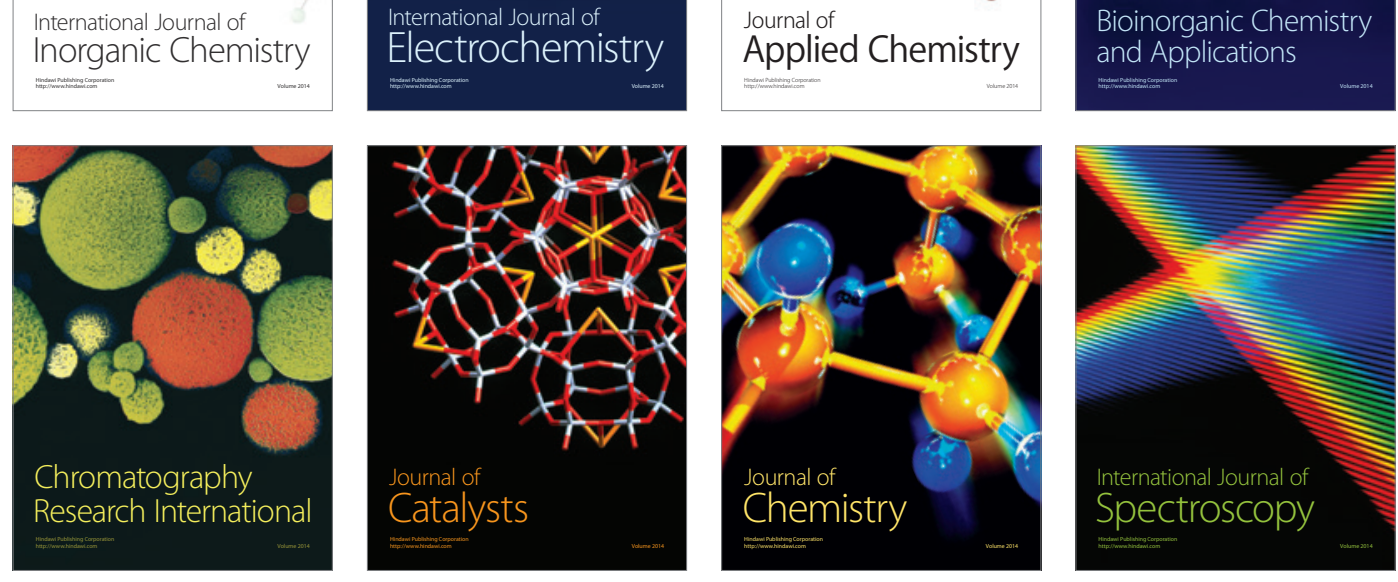